\title{
Frente a la crisis, inversión, innovación y profesionalización
}

\author{
Manel Miró Alaix | consultor en interpretación del patrimonio. Director del Área de Estudios y Proyectos de Stoa - Patrimonio,
} Turismo y Museografía

URL de la contribución <www.iaph.es/revistaph/index.php/revistaph/article/view/3415>

La inversión en patrimonio cultural en una época de recesión económica está justificada en la medida en que esa inversión incida en la generación de crecimiento económico y de empleo; en este caso, no sólo está fundamentada sino que debería ser una prioridad. El fomento de la rehabilitación, por ejemplo, ayudaría a paliar la crisis en la construcción y la mejora de la gestión y del atractivo de los sitios patrimoniales favorecería el desarrollo turístico sostenible.

Combinada con una modernización de los sistemas de gestión y una mayor profesionalización de los equipos, la inversión en patrimonio cultural sería capaz de generar un número significativo de puestos de trabajo cualificados, lo que, a su vez, permitiría ofrecer una oportunidad a los miles de jóvenes formados en la última década en las universidades españolas y que ahora se desesperan ante la falta de expectativas.

Lo que no está justificado, ni en tiempos de bonanza y aún menos en tiempos de crisis, son las inversiones públicas en patrimonio cultural que no son fruto de una planificación previa encaminada a conseguir unos objetivos económicos y sociales sino que obedecen simplemente a un capricho individual o que tienen un mero fin propagandístico.

España está salpicada de monumentos restaurados y de equipamientos construidos en los últimos años que permanecen cerrados o que no disponen de un plan de uso claro. Estas iniciativas inviables son la leña que aviva la hoguera encendida por aquéllos que siguen pensando que la puesta en valor del patrimonio es un gasto y no una inversión.

Respecto a la relación beneficios turísticos/conservación del patrimonio, en el plano teórico es evidente que existe un vínculo positivo porque, en general, aquéllos luga-

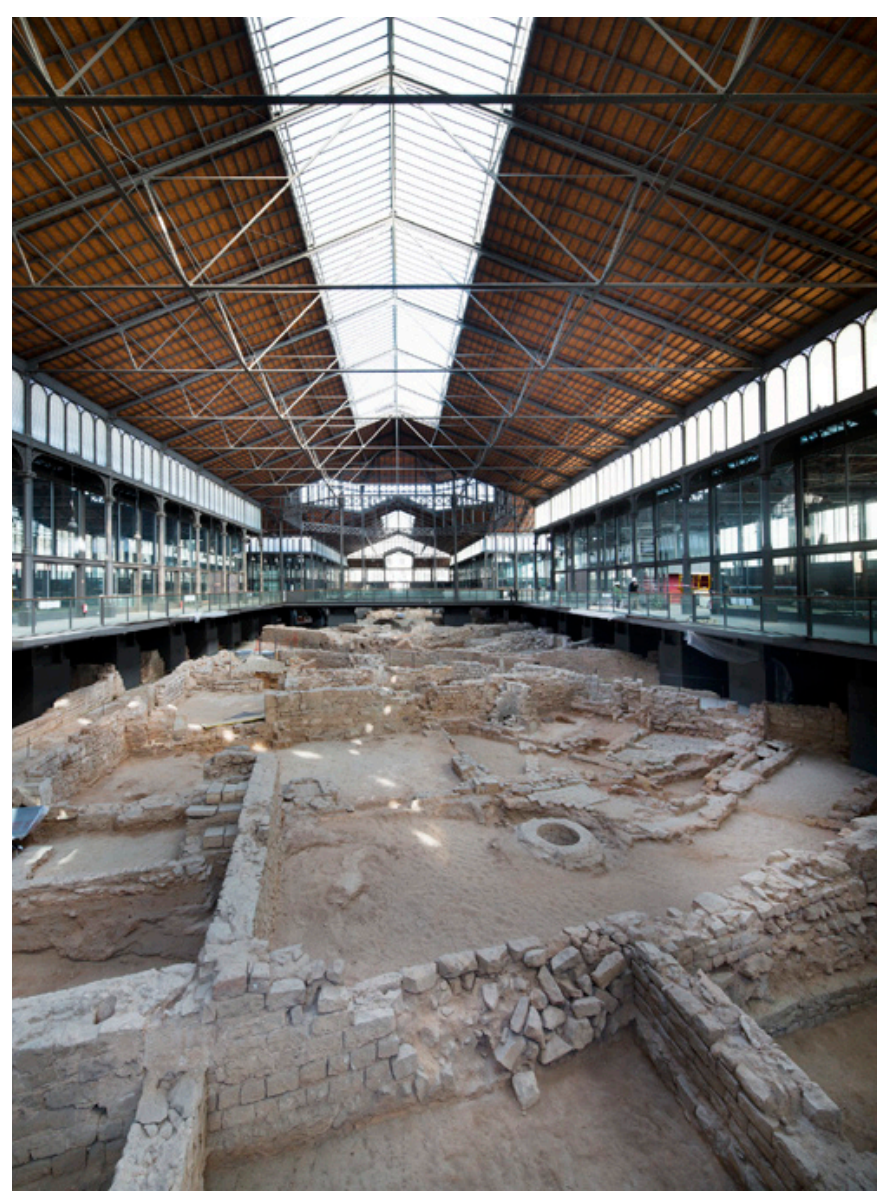

La adecuación del yacimiento arqueológico del Born en Barcelona es un ejemplo de inversión en innovación | foto Born Centre Cultural (Jordi Puig)

res que reciben un número de visitantes suficiente como para mantener un equipo profesional de gestión están mejor conservados que los que no lo tienen.

En la práctica, en nuestro país, la relación no es tan evidente y creo que el patrimonio ha proporcionado más beneficios al turismo que al revés. Esto es debido tanto a que no existe entre el empresariado turístico una conciencia mayoritaria de que una parte de sus ingresos 
debería revertir en la conservación de los recursos que hacen atractivos sus territorios, como a que no existe en las administraciones españolas, más allá de la retórica, una verdadera conciencia mayoritaria de que es necesario impulsar modelos de gestión del patrimonio con una dimensión territorial y una visión estratégica que sean capaces de aprovechar la dinámica turística en favor de la conservación del patrimonio.

\section{Equilibrio entre investigación, conservación y difusión}

El sistema patrimonial se basa en el equilibrio entre investigación, conservación y difusión. Cuando cualquiera de los tres componentes es débil, el sistema se resiente y deja de ser eficaz.

La ausencia de investigación hace que la difusión se base en discursos generales que acaban siendo poco atractivos. La ausencia de conservación hace que el patrimonio se deteriore y acabe por ser poco atractivo o inutilizable. La ausencia de difusión hace que se pierda o no se disponga de la imprescindible sensibilidad y apoyo social que el patrimonio necesita para obtener recursos para su investigación y conservación.

Lo cierto es que en nuestro país ha sido muy fácil museizar un monumento o crear un centro de interpretación sin disponer previamente de una investigación específica o de un plan de conservación.

Dado que la calidad de la oferta patrimonial es la base de su sostenibilidad y de que esa calidad precisa del equilibrio entre la investigación, la conservación y la difusión, es imprescindible que la inversión pública sea también equilibrada en los tres componentes para poder contribuir de manera eficaz al desarrollo económico y a la generación de empleo.

\section{Hacia la "gestión creativa"}

La relación entre administraciones públicas-sector privado en el campo del patrimonio cultural puede tener muchas formas y niveles que van desde el mecenazgo hasta la gestión privada de monumentos públicos.

Yo creo especialmente interesante el papel que podrían desempeñar en España organizaciones privadas no lucrativas que tuvieran como misión la puesta en valor y la gestión de bienes del patrimonio histórico. Este tipo de organizaciones podrían combinar la agilidad de la buena gestión privada con el carácter social y redistributivo propio de la buena administración pública, a la manera de lo que hace el National Trust en el Reino Unido.

Este tipo de organizaciones, dotadas de un equipo profesional, facilitarían el necesario paso que el patrimonio histórico debe dar desde la "gestión administrativa" hacia la "gestión creativa", canalizando tanto inversiones públicas como privadas e integrando e implicando a la sociedad civil en la compleja tarea de la puesta en valor del patrimonio, sea como patronos o mecenas o como voluntarios. 